\title{
EFFECT OF INCORPORATING STRONTIUM FLUORIDE AND FLUORIDE ON COMPRESSIVE AND DIAMETRAL TENSILE STRENGTHS OF BIODENTINE
}

\author{
Hosam Muhammad Elsayed **, Muhammad Shokry Ali ${ }^{* *}$, Muhammad Abbas Masoud ${ }^{* * *}$
}

\begin{abstract}
Objective: The objective of this study was aimed to evaluate the effect of incorporation strontium fluoride and fluoride on compressive and diametral tensile strengths of biodentine. Materials and Methods: Materials used in this study were divided into three main groups according to materials used Group I: Calcium silicate based material (biodentine) as a control material, Group II: Strontium fluoride modified calcium silicate based material, Group III: Fluoride modified calcium silicate based material. Each main group was subdivided into two subgroups according to test type (compressive and diametral tensile strength). Each subgroups dividing into two categories according to storage time at one week and one month. Results: According to compressive and diametral tensile strength test, biodentine recorded highest compressive and diametral tensile strength followed by strontium fluoride modified biodentine followed by fluoride modified biodentine. For storage time the four weeks compressive and diametral tensile strength is higher than Seven days. Conclusion: Modification of biodentine with strontium fluoride and fluoride don't have considerable effect on the tested properties of biodentine.
\end{abstract}

KEYWORDS: Biodentine, compressive strength, strontium fluoride, fluoride.

\section{INTRODUCTION}

Biomaterials science aims to develop materials that are ideal mechanically, physically and biologically ${ }^{(1)}$. Mineral trioxide aggregates is tricalcium (MTA) silicate cement and was initially indicated for surgical endodontics but over time found multiple other applications such as vital pulp therapy, perforation repair, apexification and apexogenesis. The main drawbacks of MTA include its potency to cause tooth discoloration, presence of toxic elements in its composition, difficult handling properties, cost ineffectiveness grainy consistency and long setting time between 40 minutes and 72 hours $^{(1)}$.

The limitations for MTA led to developing biodentine using active biosilicate technology. Biodentine sets in approximately 12 minute and is effective in pulp therapy, while being able to act as a coronal dentine replacement ${ }^{(2)}$. Also biodentine can be used for the treatment of root perforations or of the pulp floor, internal and external resorption, apical plug formation, root-end filling, pulp capping and pulpotomy but also for temporary sealing of cavities and cervical fillings ${ }^{(3)}$.

\footnotetext{
* Assistant Lecturer, Dental Biomaterials Department, Faculty of Dental Medicine, Assiut, Al-Azhar University.

** Professor and Head of Dental Biomaterials Department, Faculty of Dental Medicine, Cairo, Boys, Al-Azhar University.

*** Assistant Professor of Dental Biomaterials Department, Faculty of Dental Medicine, Cairo, Boys, Al-Azhar University.
}

- Corresponding author: hosamelsayed517@yahoo.com

DOI: $10.21608 /$ ajdsm.2020.25643.1024 
Despite biodentine having desirable properties; there is room for improvement by incorporation of the caries inhibiting fluoride and strontium species. Fluoride confers anticariogenic properties due to inhibition of plaque bacteria metabolism and impairing plaque bacteria adhesion and formation of acid resistant fluorapatite crystals ${ }^{(1)}$.

However, there is a few data are available regarding to these modification. The hypothesis of this study was that the incorporation of strontium fluoride or fluoride will change the compressive and diametral tensile strengths of biodentine.

\section{MATERIALS AND METHODS}

A total of 84 samples were prepared and equally divided into three main groups ( $\mathrm{n}=28$ samples) according to materials used Group I: Calcium silicate based material [biodentine], (Septodont, Saint Maur des Fossés, France) as a control group; Group II: Strontium fluoride modified calcium silicate based material (ADVENT, CHEBO PVT, LTO); and Group III: Fluoride modified calcium silicate based material (Prevest Den Pro Limited Unit, Industrial Estate, India). Each main group was subdivided into two subgroups according to test type ( $\mathrm{n}=14$ sample) compressive and diametral tensile strength. Each subgroups dividing into two categories according to storage time at one week and one month $(n=7)$.

\section{Compressive strength test.}

\section{Mold description:-}

In this study cylindrical split polytetrafluoroethylene mold of dimension ( $4 \mathrm{~mm}$ diameter $\mathrm{x} 6 \mathrm{~mm}$ height) with outer metallic ring were used to prepare the sample for compressive testing. Compressive strength test were done according to international standard ISO 9917-1:2007 ${ }^{(4)}$.

\section{Samples preparation:}

Modification of biodentine was prepared by adding $10 \%$ by weight of fluoride and strontium fluoride to biodentine powder. Since biodentine powder weight is $0.7 \mathrm{gm}$, so the weight of fluoride and strontium fluoride added to the biodentine powder was calculated using the following equation $=(0.7 \times 10) / 100=0.07 \mathrm{gm}$.

Fluoride and strontium fluoride $(0.07 \mathrm{gm})$ modifiers were added to the biodentine powder and mixed it at 3000 RPM for 10 seconds. This was to ensure dispersion of fluoride and strontium fluoride into the biodentine powder as extensively as possible. Five drops of liquid added to the powder and triturating in amalgamator for 30 seconds in 3000 RPM leading to the formation of a paste of creamy consistency.

The mold was supported by a larger glass plate and covered with a polyester film. The material were prepared and filled the mold using a plastic spatula to condense the material. Another glass plate also covered with polyester film in such a way that the plates touched the entire mold in a uniform manner. The assembly was placed in an incubator (3M, Advanced Technology) for $37{ }^{\circ} \mathrm{C}$, $95 \%$ relative humidity for a period corresponding to three times of the setting time. The materials were removed from the mold and any excess material were removed.

\section{Measurement of compressive strength test:-}

All samples were individually and vertically mounted on a computer controlled materials testing machine (Model 3345; Instron Industrial Products, Norwood, MA, USA) with a load cell of $5 \mathrm{KN}$ and data was recorded using computer software (Bluehill Lite Software Instron ${ }^{\circledR}$ Instruments). The samples were statically loaded (in compression manner) using stainless-steel rod ended with flat plate $(40 \mathrm{~mm} \times 60 \mathrm{~mm})$ attached to the upper movable compartment of the machine at a crosshead speed of $1 \mathrm{~mm} / \mathrm{min}$ until failure .

The maximum failure load was recorded in $\mathrm{N}$ and converted into $\mathrm{MPa}$. The compressive strength was calculated from the recorded peak load divided by sample surface according to the following equation; 
Compressive strength $=4 \mathrm{P} / \pi \mathrm{D}^{2}$ Where $\mathrm{P}$ is the maximum load applied in Newton and D is the diameter of the sample in millimeters. Value were recorded, tabulated for each group.

\section{Determination of Diametral tensile strength test:}

\section{Mold description:}

In this study circular split metallic mold with outer metallic ring ( $6 \mathrm{~mm}$ diameter $\mathrm{x} 4 \mathrm{~mm}$ height) were used to prepare the samples for diametral tensile strength test.

Samples were prepared as mention in compressive strength test.

\section{Measurement of diametral tensile strength test:}

The samples were statically loaded diametrically using stainless-steel rod with flat end $(10 \mathrm{~cm}$ width $5 \mathrm{~cm}$ breadth) attached to the upper movable compartment of the testing machine at a crosshead speed of $1 \mathrm{~mm} / \mathrm{min}$ until failure. The maximum failure load was recorded in $\mathrm{N}$ and converted into $\mathrm{MPa}$. The diametral compressive strength was calculated from the following equation; $\delta=2 \mathrm{P} / \pi$ D T Where; $\delta=$ Diametral tensile strength $(\mathrm{MPa})$ $\mathrm{P}=$ load at failure $(\mathrm{N}), \pi=3.14, \mathrm{D}=$ disc diameter $(\mathrm{mm})$ and $\mathrm{T}=$ disc thickness $(\mathrm{mm})$.

Data analysis was performed in several steps. Initially, descriptive statistics for each group results. Two way ANOVA was done for comparing cement and storage media effect on different variable studied. One way ANOVA followed by pair-wise Turkey's post-hoc tests were performed to detect significance between each cement groups and t-test for subgroups. Statistical analysis was performed using Assistant 7.6 statistics software for windows (Campina Grande, Paraiba state, Brazil). P values $\leq 0.05$ are considered to be statistically significant in all tests.

\section{RESULTS}

\section{Compressive strength}

Compressive strength results (Mean \pm SD) measured as function material group and storage time are summarized in table (1).

After seven days; it was found that biodentine group recorded statistically non-significant ( $>0.05$ ) highest compressive strength mean values $(42.46 \pm 8.1 \mathrm{MPa})$ followed by strontium fluoride (SF) modified biodentine group (40.36 $\pm 6.2 \mathrm{MPa})$ while the lowest statistically non-significant $(p>0.05)$ compressive strength mean values was recorded for fluoride $(\mathrm{F})$ modified biodentine group (38.25 $\pm 4.3 \mathrm{MPa})$.

After four weeks; it was found that biodentine group recorded statistically non-significant $(\mathrm{p}>0.05)$ highest compressive strength mean values $(47.6 \pm 10.12 \mathrm{MPa})$ followed by SF modified biodentine group $(42.4 \pm 5.5 \mathrm{MPa})$ while the lowest statistically non-significant $(\mathrm{p}>0.05)$ compressive strength mean values was recorded for $\mathrm{F}$ modified biodentine group $(41.93 \pm 6.3 \mathrm{MPa})$.

\section{Seven days vs. Four weeks}

For all experimental groups it was found that four weeks compressive strength mean values were higher than seven days means values. There were statistical non-significance ( $>0.05$ ) between seven days and four weeks as proved by paired t-test.

TABLE (1) Comparison of compressive strength results $($ Mean \pm SD) as function of material groups and storage time

\begin{tabular}{|c|c|c|c|c|}
\hline \multirow{2}{*}{ Variables } & \multicolumn{2}{c|}{ Storage time } & t-test \\
\cline { 3 - 5 } & Seven days & Four weeks & P value \\
\hline \multirow{2}{*}{$\begin{array}{c}\text { Material } \\
\text { group }\end{array}$} & \begin{tabular}{c} 
Biodentine \\
\cline { 2 - 5 } \\
bF modified \\
\cline { 2 - 5 }
\end{tabular} & $42.46 \pm 8.1$ & $47.6 \pm 10.12$ & $0.3145 \mathrm{~ns}$ \\
\hline & $\begin{array}{c}\text { F modified } \\
\text { biodentine }\end{array}$ & $38.25 \pm 4.3$ & $41.93 \pm 6.3$ & $0.2262 \mathrm{~ns}$ \\
\hline ANOVA & P value & $0.4805 \mathrm{~ns}$ & $0.323 \mathrm{~ns}$ & \\
\hline
\end{tabular}

ns; non-significant $(P>0.05) *$; significant $(P<0.05)$ 


\section{Diametral tensile strength}

Diametral tensile strength results $($ Mean \pm SD) measured as function material group and storage time are summarized in table (2).

After 7 days; it was found that SF modified biodentine group recorded statistically nonsignificant $(\mathrm{p}>0.05)$ highest diametral tensile strength mean values $(6.2 \pm 1.4 \mathrm{MPa})$ followed by biodentine group $(6.19 \pm 1.1 \mathrm{MPa})$ while the lowest statistically non-significant $(\mathrm{p}>0.05)$ diametral tensile strength mean values was recorded for $\mathrm{F}$ modified biodentine group (5.27 $\pm 0.7 \mathrm{MPa})$.

After four weeks; it was found that biodentine group recorded statistically non-significant ( $p>0.05)$ highest diametral tensile strength mean values $(8.07 \pm 1.9 \mathrm{MPa})$ followed by $\mathrm{SF}$ modified biodentine group $(7.9 \pm 1.6 \mathrm{MPa})$ while the lowest statistically non-significant $(p>0.05)$ diametral tensile strength mean values was recorded for $\mathrm{F}$ modified biodentine group $(5.9 \pm 1.05 \mathrm{MPa})$.

$\underline{\text { Seven days vs. Four weeks }}$

For all experimental groups it was found that four weeks diametral tensile strength mean values were higher than seven days means values. There was statistical non-significance $(p>0.05)$ between seven days and four weeks as proved by paired t-test.

TABLE (2) Comparison of diametral tensile strength results (Mean $\pm \mathrm{SD})$ as function of material groups and storage time

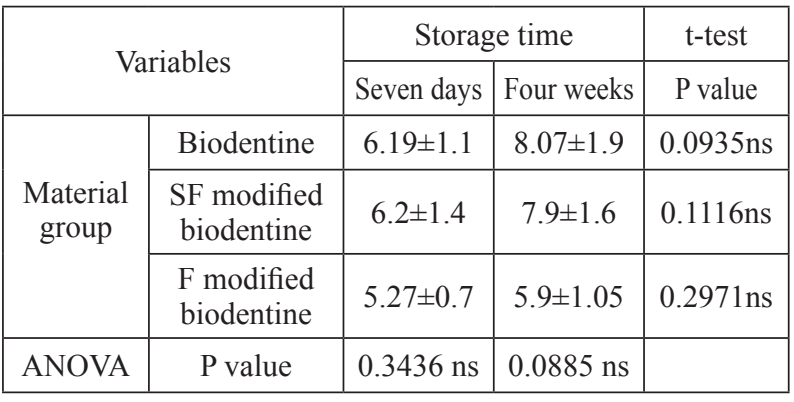

ns; non-significant $(P>0.05)$ *; significant $(P<0.05)$

\section{DISCUSSION}

Dental material science is always evolving with effort geared at developing materials that are able to not only restore form and function but aesthetics as well. The aim of biomaterial scientists has been to develop materials that are durable and satisfy mechanical, physical, chemical and biological ideals set by material standards governing bodies ${ }^{(1)}$.

Biodentine can be used for the treatment of root perforations or of the pulp floor, internal and external resorption, apical plug formation, root-end filling, pulp capping and pulpotomy but also for temporary sealing of cavities and cervical fillings ${ }^{(3)}$.

In the face of biodentine which has desirable properties; there is room for improvement by incorporation of the caries inhibiting fluoride and strontium additives. Fluoride confers anticariogenic properties due to inhibition of plaque bacteria metabolism and impairing plaque bacteria adhesion and build up and formation of acid resistant fluorapatite crystals ${ }^{(1)}$.

Compressive strength is considered as one of the main physical characteristics of hydraulic cements. Considering that a significant area of usage of products such as biodentine is vital pulp therapies it is essential that the cement has the capacity to withstand masticatory forces in other words, sufficient compressive strength to resist external impacts ${ }^{(5)}$.

Also tensile strength is considered as one of the determining measures for mechanical properties of dental materials. Direct measurement of tensile strength of brittle materials is difficult. Therefore, the diametral tensile strength (DTS) test has been adopted which is an accepted standard to measure the tensile strength of materials ${ }^{(6)}$.

At one week the results of the present study show that biodentine group recorded highest compressive strength followed by strontium fluoride modified biodentine group while the lowest compressive 
strength was recorded for fluoride modified biodentine group. The result of the present study was in agreement with previous studies Sheykhrezae et al. ${ }^{(7)}$ Alzraikat et al. ${ }^{(8)}$ Simila et al..$^{(9)}$ Lucas et al. ${ }^{(10)}$ Kayahan et al. ${ }^{(5)}$ Ranjkesh et al. ${ }^{(11)}$.

This could be attributed to its low water/powder ratio required for good workability of the cement this was achieved by incorporating a hydro-soluble polymer into the liquid component of the cement in addition to adding a water soluble polycarboxylate to the cement's powder ${ }^{(8)}$. Therefore, the resulting structure of the material has lower porosity and consequently higher compressive and diametral strength $^{(10)}$. Also biodentine is based on tricalcium silicate in addition to setting accelerators (calcium chloride) and other components to improve strength and manipulation ${ }^{(12)}$.

Also biodentine and modifications have lower liquid to powder ratio which needs more mixing liquid to achieve desirable consistency to work. Thus, decreased liquid-to-powder ratio can be an explanatory factor for the enhanced mechanical properties of calcium silicate based compositions. However, the size of cement particles can also influence the rate of hydration and consequently influence the strength and setting characteristics of calcium silicate cements ${ }^{(13)}$.

After four weeks all groups show higher strengths with time owing to the slow reaction of the dicalcium silicate phase which typically transforms into a calcium silicate hydrate, which confers strength. It is possible that manipulation variability arising from proportioning the biodentine liquid as drops, rather than precisely measured volume could account for this ${ }^{(1)}$.

On the other hand the result of the present study showed disagreement with study by Grech et al. ${ }^{(14)}$. They found the compressive strength of biodentine to be much lower because they tested the samples at one time point and they stored their samples in a gel of Hanks Balanced Salt Solution to more closely mimic those of the oral environment.
The result of the present study was in contradictory with Cho et al. ${ }^{(15)}$, they found that humidity can adversely affect the diametral tensile strength :

The hypothesis of this study was that the incorporation of strontium fluoride or fluoride will change the compressive and diametral tensile strengths of biodentine, was rejected as the differences although lower where not significant.

\section{CONCLUSION}

There was no single modification that achieved all levels of improvement on the tested properties so, modification of biodentine with strontium fluoride and fluoride did not considerably effect the tested properties of biodentine.

\section{REFERENCES}

1. Simila HO, Karpukhina N, Hill RG. Bioactivity and fluoride release of strontium and fluoride modified biodentine. Dental Materials. 2018;34(1):1-7.

2. Laurent P, Camps J, De Méo M, Déjou J, About I. Induction of specific cell responses to a $\mathrm{Ca} 3 \mathrm{SiO} 5$-based posterior restorative material. Dental materials. 2008;24(11):1486-94.

3. Dammaschke T. Direct pulp capping. Dental materials.. 2011;27(8):88-94.

4. International Organization for Standardization (ISO). 9917-1: dentistry-water-based cements - part 1: powder/ liquid acid-base cements. Geneva, Switzerland: International Organization for Standardization. 2007.

5. Kayahan MB, Nekoofar MH, McCann A, Sunay H, Kaptan RF, Meraji N, et al. Effect of acid etching procedures on the compressive strength of four calcium silicate-based endodontic cements. Journal of Endodontics. 2013;39(12):1646-8.

6. Murray Pe, About I, Franquin J-C, Remusat M, Smith Aj. Restorative pulpal and repair responses. Journal of the American Dental Association. 2001;132(4):482-91.

7. Sheykhrezae MS, Meraji N, Ghanbari F, Nekoofar MH, Bolhari B, Dummer PM. Effect of blood contamination on the compressive strength of three calcium silicate-based cements. Australian Endodontic Journal. 2018;44(3):255-9.

8. Alzraikat H, Taha NA, Salameh A. A comparison of physical and mechanical properties of biodentine and mineral trioxide aggregate. Journal Research of Medical Dental Science . 2016;4(2):121-6. 
9. Simila H, Karpukhina N, Hill R. Physicomechanical properties of strontium and fluoride modified biodentine . East African Medical Journal. 2017;94(11):923-34.

10. Lucas CdPTP, Viapiana R, Bosso-Martelo R, GuerreiroTanomaru JM, Camilleri J, Tanomaru-Filho M. Physicochemical properties and dentin bond strength of a tricalcium silicate-based retrograde material. Brazilian Dental Journal. 2017;28(1):51-6.

11. Ranjkesh B, Isidor F, Dalstra M, Løvschall H. Diametral tensile strength of novel fast-setting calcium silicate cement. Dental Materials Journal. 2016;35(4):559-63.
12. File BS. Active biosilicate technology, septodont. SaintMaur-des-Fossés Cedex: R\&D Department. 2010.

13. Celik I. The effects of particle size distribution and surface area upon cement strength development. Dental Materials. 2009;188(3):272-76.

14. Grech L, Mallia B, Camilleri J. Investigation of the physical properties of tricalcium silicate cement-based root-end filling materials. Dental Materials. 2013;29(2):20-28.

15. Cho E, Kopel H, White SN. Moisture susceptibility of resin-modified glass-ionomer materials. Quintessence International. 1995;26(5):34-40. 